\title{
The Hindrances in Translating Specific Cultural Concepts from Arabic into English
}

\author{
Amin Ali Almubark, Dr.AmerrudinAbd. Manan,Associate Professor \\ KhairiObaidTayyeh Al-Zubaid \\ Faculty of Education, UniversitiTeknologi Malaysia54100, JalanSemarak, Kuala Lumpur, Malaysia
}

\begin{abstract}
This paper investigates problems faced by undergraduate students in Sudan majoring in English language when translating specific cultural concepts from Arabic language into English language. To attain this aim, the researcher randomlyselected 100 undergraduate students who were registered for the B.A program inthe Department of English at Al Imam AlMahdi University in Sudan during the 2012/2013 academic year. The researchers carried out a translation test that consisted of 18 sentences which the learners were then required to translate from Arabic into English. Each sentence comprised of specific cultural concepts based on Newmark's (1988) classification of cultural terms. The researchers also carried out interviews with lecturers who specialize in translation to get further data from their point of view concerning these difficulties, the reasons and their proposed solution. The findings show that the undergraduate learners faced various types of complications when translating specific cultural concepts. These difficulties are frequently associated with; 1) translating specific cultural concepts, 2) unsuccessful attempts to attain the sameness in English language, and 3) lack of knowledge of translation techniques and translation strategies. Based on this result, this research work proposes a solution to narrow the gap between specific cultural concepts such as figuring out programs that deals with specificcultural conceptsthat suit translators.
\end{abstract}

Keywords: problems, cultural, specific concepts Arabic/English

\section{Introduction}

A translation of one language into another is irreplaceable in today's world whether it is for educational, socioeconomic, political and religious development purposes among peoples of dissimilar linguistic identities. The invention of the Internet and new technological advances in communication has increased cultural exchanges between people of different nations around the world. This has necessitated translators to search for new strategies to handle such exchanges and more practical methods to effectively translate as much as possible.

Still, there are problems which must be addressed, such as the challenges that appear from the lack ofunderstandingofspecific cultural concepts between Arabic and English languages which exist because of the cultural variations. Scholars have done research on the concept of non-equivalence, which means that the target language has no similar correspondence for a term or expression found in the source language. Therefore, in the process of translating an idea from Arabic language into English language, the translator also has to contend with two dissimilar cultures at the same time.

\section{Questions and Objectives of the Study}

This paper intends to investigate the problems faced by undergraduate students majoring in English at Al Imam AlMahdi University in Sudan in translating specific cultural concepts from the Arabic language to the English language. It also attempts to clarify the elements that cause these difficulties and gives some suggestions on how to overcome them.

Toattain the aforementioned aim, the paper answered the question; what are the difficulties faced bythe undergraduate students who studyEnglish language at Al Imam AlMahdi University in Sudan whentranslating specific cultural concepts from Arabic language into English language?

\section{Significance of the Study}

Research has been carried out on the problems that are faced by translators in translation in general. But practical studies which focus on translation involving specific cultural concepts in the Arab nations are comparatively small. The attention has been on specific language constructs like proverbs, collocations and idioms.Consequently, this paper is designed to fill what appears to be a gap in literature. The findings of this paper and suggestions for future study will helppeople involvedin translation to understand specific cultural concepts problem and be aware of such difficulties. 


\section{Review of Related Literature}

Empirical evidence has shown that researchers have different perspectives to the non-equivalence issue. For example, Shammas (2010) addressed the main problems and hindrances faced by the Master of Arts students of translation at Petra University, Jordanand Damascus University, Syria. In his research work, the main focus was linguistic mistakes and cultural differences in translating from Arabic into English. The linguistic mistakes adapted the syntactic and morphological dimensions of linguistics and the semantic character of word alternative and collocation. The cultural dissimilar cases reflected various numbers of social values in the native Arabic source language and English target language. The linguistic errors and the cultural dissimilar cases are likely to bring pragmatic failures in understanding the English target concepts, but to different degrees.

In addition, Dweik and Shakra (2011)carried out informal open-ended meetings with professionals in the area of translation to get more data from a specialists'outlook in viewing these difficulties. The outcome of thatresearch showed that theundergraduate learners encountered various types of challenges when translating cultural concepts. These difficulties are mainly associated with; first, unawareness with cultural expressions; second, failure to attain the correspondence in the target language; third, ambiguitiesof some cultural concepts and fourth, shortage in acquaintance of translation methods and translation techniques. In light of these issues, the researchers recommend reducing the differences between cultures throughcreatingextra programs whichdeal with cultural dissimilarities, awareness and consciousness, particularly preparing the translator alongside academic programs.

Moreover, Bahameed (2008)pointed out that it is true in some circumstances, the Arab translator may find particular lexical terms in Arabic language that have no equivalents in the English language since such concepts do not exist in the English culture. From anArabic language to the English language intercultural translation aspect, examples can clarify the issue of translatable versus untranslatable terms. These examples include: ستحور sahuur (a meal consumed before the start of fasting); andةkhalwah (single man and woman observed in a situation where there is nobody else). The challenges of translating such words are due to the lexical gaps resulting from the cultural variations between the two languages.

Furthermore, Saleh et al. (2011) stated that non-equivalence is a main source ofproblems in translating, especially the strange names given to dishes in which translators, even professionals, are unaccustomed with. This would needthe highest effort in searching, depending on specialized dictionaries or personal interviews. Otherwise, the borrowing strategy is desirable to avoid inexact translations. Moreover, some food terms have cultural or religious implications which make them sensitive in translation thus requiring enough attention on the part of the translator to produce satisfactory translations that respect the cultural and religious values of the target readers.

Paluszkiewicz-Misiaczek (2005)pointed out that loaning words is useful when dealing with culturespecific concepts in translation. This also assists in the situation where a very new concept is introduced. The loan term can, and very frequently be followed with an explanation, which is very helpful when the term in question is mentioned several times in text. Then, once defined, it can only be applied if the reader does not have difficulties with accepting it and his consideration are not obstructed by other long explanations. The choice with which translators use loan terms depends on the purpose and the kind of words they used particularlyanywherein the text. Furthermore, the translator needs to protect and display some aspects of the original culture.

Al-Masri (2009) focused on cultural translation, especially addressing the issue of cultural nonequivalences which occur in the translation of Arabic cultural concepts. He reviewed the translation strategies that led to cultural incorrect translation and to highlight the important task of the translator as a cultural insider. He investigates the non-equivalence figurative language from Arabic language into English. He concludes in his study with an indication that a translator has to understand the role of a cultural insider for both texts in order to provide a more reliable cultural translation.

Shunnaq (1993) focused on the two semantic cultural concepts; emotiveness and reoccurrence. The research recommends that a translator of Arabic political speech must give high consideration to the aforementioned semantic aspects. The translator must be conscious that what may be a useful repetition and emotiveness in the Arabic language may appear to be irrelevant and redundant in the English language. Furthermore, sentiment can be communicated by specific semantic ideas such as exaggeration, repetitionand similes.

Ghussain and Al Latif (2003)pointed out that, translation complications often resulted from of the dissimilarities between the source and the target language's cultures and linguistic rules. Moreover, Ghussain and Al Latif (2003)highlighted that their research is a practical step towards recognizing cultural and linguistic barriers in translation from the English language to the Arabic language.

Likewise, Ghussain and Al Latif (2003)analysed 177 texts and recognized several linguistic and cultural difficulties in their translations. Results showed that cultural obstacles are typically the result of variations between Western; especially British's culture and Arab Palestinian's culture. Students' selection of 
cultural literal translation, transplantation, translation by addition, translation by omission and the tendency of some students' to reflect their personal experiences on translating cultural words from Arabic language into English language.

Maasoum and Davtalab (2011)stated that among various fields such as material culture,ecology, organizations,social culture, gesture and habits, the terms related to the realms of material cultureoccurred more frequently than those in other domains. The investigation of cases in this study recommends that among all the other strategies, in most situations the students applied general words and borrowing more than other approaches to deal with the lexical gap. These procedures are useful in various situations and the translator can perform his or her translation to be more trustworthy and real.

In addition,Maasoum and Davtalab (2011)said that, in a few situations, one or more method were recommended for every field. It does not imply that a translator should select a particular approach or method to translate. It is understandable that the translator should select suitable strategy based on the condition, context and the objectiveof the translation.

$\mathrm{Wu}$ (2008) also mentioned that the importance of translation is to change a wordor phrase from one language to another language. $\mathrm{Wu}$ (2008) stated that the original meaning of an expression should be kept in the same version in the translation without any addition or removal. Therefore, Wu (2008)stated that there are two factors in translation, accuracy and expressivity which a good translator must always consider.

Zughoul and Abdul-Fattah (2003)studied how university students majoring in English language could use English collocations correctly in translation. The translation test containing 16 Arabic collocations was given to both undergraduate and graduate students majoring in English language. The initial group was given an English translation in a multiple-choice form whereas; the other was given a projectfor the translation exercise. The result affirmed that Arab learners of English at various levels faced obstacles in translating English collocations because of their cultural differences.

The study examined the collocation errors committed by the graduate translation students in a corpus of varied texts. The results showed that there was some weakness in proficiency in English lexical use in general and collocation clusters in particular. This finding is in line with the common observation and research assertion that word collocation is a challenging area even for advanced English learners as a Foreign Language users. It thus entails a formal, explicit focus on lexis, including collocation, in the teaching programs at all levels. It also suggests that graduate students of translation should make frequent reference to collocation dictionaries which display a wide range of word collocations, an advantage that is lacking in most of the ordinary current dictionaries. Besides, the study showed a differential trend of performance patterns implied by the difference in the subjects' means on the investigated collocation types.

Deeb (2005) also mentioned the problems in translation from the English language to the Arabic language. She provideda classification criterion by raking the problems in translating from English to Arabic that was developed through two empirical research studies.By comparing the two groups' performance, the researcher could also find out the effects of translation experience/proficiency on the type and severity of problems.

The taxonomy consists of four levels: supra, main, sub and sub-sub categories. The supra category includes problems of source languagecomprehension, target languageproduction and translation process. The main category includes micro-language, macro-text level and strategy problems. The sub-category includes problems of grammar, vocabulary, spelling, rhetorical and stylistic devices, cohesion, register and style, background knowledge and culture. The sub-sub categories include forty seven categories such as problems of word order, fixed expressions, spelling slips, irony, omission and additions.

In this study it was found that one of the central problems manifested by errors in the subjects' translations is lack of cohesion. This often leads to failure to translate the source language text message as shown by the reaction of the target language recipientresulting in the text losing one of its main factors, which is acceptability.

Furthermore, Abbadi (2008) investigates translation problems from English into Arabic faced by students. It provides a practical study regarding investigation of the real world translation. The objective of the study depended on the analysis of a translation corpus composed of one hundred translations of the source language texts created by professional translators. The analysis of errors indicated translation problems at the textual level, grammatical and lexical.It is also mentioned that, additional steps were used to analyze the mistakes present in the corpus, which are classification and target language readership assessments. The fundamental problems were then explained in light of the inseparably difficult nature of some categories, as described by available literature and translator capability.

Shobaky (2008)also introduced some of the difficulties encountered by the linguistic translators from Arabic to English. In addition, the study was an attempt to determine the causes of obstacles in translation. The debate demonstrated that in order to give an equivalent impact of the source text, the translator must have good 
knowledge of the source language and its culture; more so the comprehension of the target language. Furthermore, Shobaky (2008) shows that the translation between two different stem languages for example the Arabic and English, is a difficult task. Therefore, a complete equivalent translation is a fantasy. Finally, the translation obstacles could be because of linguistic or cultural difficulties, but the main two reasons overlap each other.

In addition, Aziz and Lataiwish (2000)pointed out that all the cultural aspects have great significance to translation. And it seems that non-equivalence cultural equivalence appeared to likely block the progression of translation. The first technique provides a solution to this problemas explained in the footnote. Secondly, the method is to enlarge cultural consciousness of both translators and the reader of the source language through an over-expanding cognitive mapping and wider-world view. This is to make sure the understanding of the differences in the target language with the source language without affecting the potential meaning and connotation of the changes in the target language text.

Finally, Bekkai (2010) tried to examine the issues of translating cultural loaded proverbs and idioms, using a random sample of twenty five third year students at the English Department in Mentouri University of Constantine. Cultural differences are the aspects of possible difficulties in translation from Arabic to English. These obstacles occur when one form of behaviour in one culture is almost nonexistence in another, or when the similar cultural concept is designed and interpreted dissimilarly by both cultures. Therefore, it is not sufficient for translators to be bilingual, but they must be bicultural as well. The participants were assessed on the basis of a model answer suggested by two experts' translationlecturers of the English Department at Mentouri University in Constantine.

The success of the translators' activity to overcome cultural problems depends on the capability of awareness on how culture generally functions to comprehend the unforeseen cultural meanings formed by values and conventions. This is in order to be able to match all of these with suitable linguistic and cultural responses.

To conclude, the studies conducted on translation issues are focused on various types of translation problems. This study is an approach to the details of problems of translating from Arabic to English with some significant non-equivalence specific cultural concepts at the word level which are faced by the undergraduate students at the university level in Sudan. The reviews of the previous studies help a great deal in identifying translation barriers in general and in determining which are significant to be studied and which are not. The findings obtained from the previous studies played a role in deciding on the frame of concepts to be included in the study that should be selected. The current study deals withnon-equivalence of specific cultural concepts at the word level that have not been discussed widely in the previous studies such as cultural problems related to food, religion and marriage.

\section{Sample of the Study}

In this paper, the sample selected for this research consists of the final year Al Imam Al Mahdi University's students from the Faculty of English language in Sudan. There were various reasons why this group of students is preferred as the respondents. First, the criteria of selecting the students were based on their performance on their secondary school exams, as they were expected to have obtained a total mark of above $70 \%$ in order to join the English language program. Secondly, they were at the end of their undergraduate course and would soon be posted to different schools all over Sudan to start their teaching career. Third, they were native speakers of the Arabic language. They were 100 students of both sexes, aged between 20 and 22 years old.

\section{Instruments of the Study}

In this research, the researcher used two instruments to collect data. First, a translation test was carried out specially to meet the objectives of this present paper. The test contained 18 specific cultural concepts from Arabic language (Appendix A). A letter which described the purpose of the research and the formal permission to conduct out the test was given to the respondents.

The second tool was an informal open-ended interview. The corresponding researcher interviewed four lecturers whose teach translation courses. Every interview consists of three topics. The question was created to associate the obstacles that the students faced, the reasons of the difficulties and resolutions to overcome the difficulties.The interview question: what can be done in your view to simplify these difficulties as well as simplifying the translation task for the students?

\section{Test Findings}

The non-equivalence specific Islamic cultural concepts represent an actual barrier to the students in translating from the Arabic language to the English language. Answers from the test were presented in five categories; the wrong word, the right word, transliteration, incomplete meaning and no answer. 


\subsection{Specific Islamic cultural concepts}

The descriptive analysis of the specific Islamic cultural concepts in Table 1 and Figure 1 shows the students' performance in translating specific Islamic cultural concepts like عِمَادَالدّين (emadaldien) which means one of the Five Pillars of Islam, عدأَ (uddah) which meansthe period a woman must follow after the loss of her husband or after a separation الْغُفْرَان (algofran)which meansforgiveness, القبلة (alquiba) which meanspointing their pray to God only, الْعصر (alasr) which meansthe afternoon daily prayer recited by practicing Muslims, الطََّارَ (clarity)which means theclarity of the entire body with the nostrils, mouth and head,from Arabic to English language. All the participants did the translation of non-equivalence specific cultural concepts test. According to the frequency test for the specific Islamic cultural concepts terms, a majority of the respondents gave wrong answers to all the concepts in the test. Specifically, among the one hundred participants seventyone percent providedwrong answersto all concepts in the test, while only sixteen percent of them gave the right answers to all the concepts, hencethis should be considered as a major problem in translation.

However, in the transliteration of the specific Islamic cultural concepts terms showed only twelve percent among the hundred participants gavethe right answers but without an explanation. From the total participants, one percent was unable to give an answer at all. Figure 1 showsthe performance for all the participants in the translation test.

Table1 specific Islamic cultural concepts

\begin{tabular}{|l|r|r|r|r|}
\hline & Frequency & Percent & Valid Percent & $\begin{array}{c}\text { Cumulative } \\
\text { Percent }\end{array}$ \\
\hline right word & 16 & 16.0 & 16.0 & 16.0 \\
wrong word & 71 & 71.0 & 71.0 & 87.0 \\
Transliteration & 12 & 12.0 & 12.0 & 99.0 \\
Incomplete meaning & 1 & 1.0 & 1.0 & 100.0 \\
Total & 100 & 100.0 & 100.0 & \\
\hline
\end{tabular}

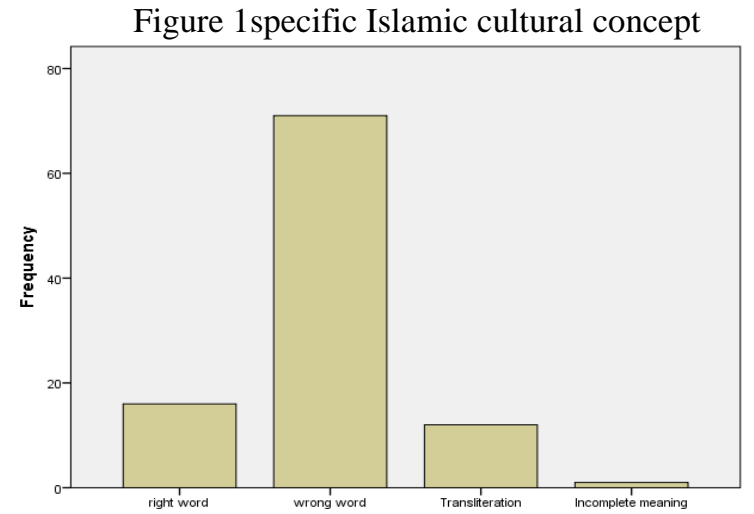

\subsection{Specific food culture terms in Sudan}

The descriptive analysis in the terms of specific food cultural concepts in Table 2 and Figure 2 shows the students' performance in translating specific food cultural concepts from Arabic into English. The specific food cultural concepts were, الملوخية) (mloukhiya) which meansthe blades of corchorus kinds used as a vegetable in Sudan, الْحِلْبَة (hilba)term refers to small green seeds, which are used as a remedy and/or a food supplement when one has stomach related problems, شَيُشَكَبَابُ (kebab)which refers to food that is prepared over or close to flames,

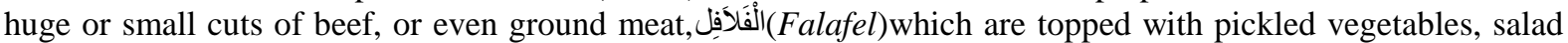

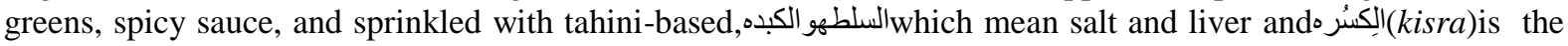
traditional food in Sudan, which means thin flat bread made from sorghum.According to the frequency test a majority of the respondents gave wrong answers to all specific food cultural concepts. Specifically, sixty-four percent of participants gave wrong answers while only seven percent of them gave right answers to all specific food cultural concepts, which again should is considered as a major problem. However, in using the transliteration method to translate the specific food cultural concepts,it shows only twenty-five percent amongst all participants gave right answers without an explanation. From all participants, only three percent provided incomplete meaning while one percent gave no answer. Figure 2shows the performance for all the participants in the translation test. 
Table 2 Specific food culture terms in Sudan

\begin{tabular}{|c|c|c|c|c|c|}
\hline & & Frequency & Percent & Valid Percent & $\begin{array}{c}\text { Cumulative } \\
\text { Percent }\end{array}$ \\
\hline \multirow{6}{*}{ Valid } & right word & 7 & 7.0 & 7.0 & 7.0 \\
\hline & wrong word & 64 & 64.0 & 64.0 & 71.0 \\
\hline & Transliteration & 25 & 25.0 & 25.0 & 96.0 \\
\hline & Incomplete meaning & 3 & 3.0 & 3.0 & 99.0 \\
\hline & No answer & 1 & 1.0 & 1.0 & 100.0 \\
\hline & Total & 100 & 100.0 & 100.0 & \\
\hline
\end{tabular}

Figure 2 Specific food culture terms in Sudan

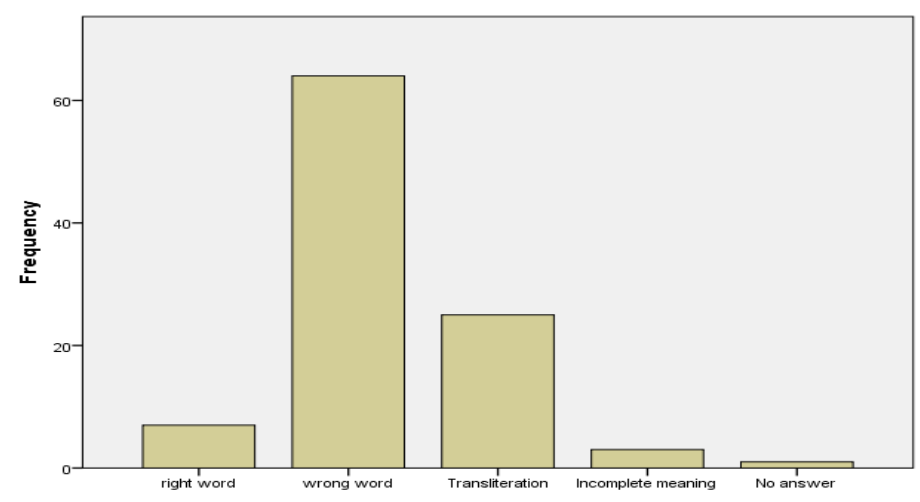

\subsection{Specific marriage culture terms}

The descriptive analysis of the specific marriage cultural concepts terms in Table 3 and Figure 3 shows the students' performance in translating specific marriage cultural concepts from Arabic into English. According to the frequency test in the specific marriage cultural concepts terms

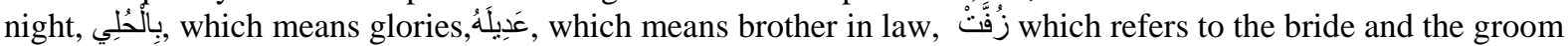
sit on a dais, which normally consists of two luxurious chairs in front of the guests, dowry, العِّمَامة which refers to Sudanese communities, the groom must wear the turban during the lunchtime to greet the guests, among the hundred participants majority of the respondents gave the wrong answer. To be specific, sixty percent of the respondentsgave the wrong answers to all specific marriage cultural concepts, while thirty-two percent of them gavethe right answers. This is also considered as a major problem. However, in using the transliteration method to translate the specific marriage cultural concepts, it shows that eight percent among of all participants gave the right answers without an explanation. Figure 3 shows the performance for all the participants in the translation test.

\begin{tabular}{|c|c|c|c|c|c|}
\hline & & Frequency & Percent & Valid Percent & $\begin{array}{l}\text { Cumulative } \\
\text { Percent }\end{array}$ \\
\hline \multirow{4}{*}{ Valid } & right word & 32 & 32.0 & 32.0 & \multirow{4}{*}{$\begin{array}{r}92.0 \\
100.0\end{array}$} \\
\hline & wrong word & 60 & 60.0 & 60.0 & \\
\hline & Transliteration & 8 & 8.0 & 8.0 & \\
\hline & Total & 100 & 100.0 & 100.0 & \\
\hline
\end{tabular}

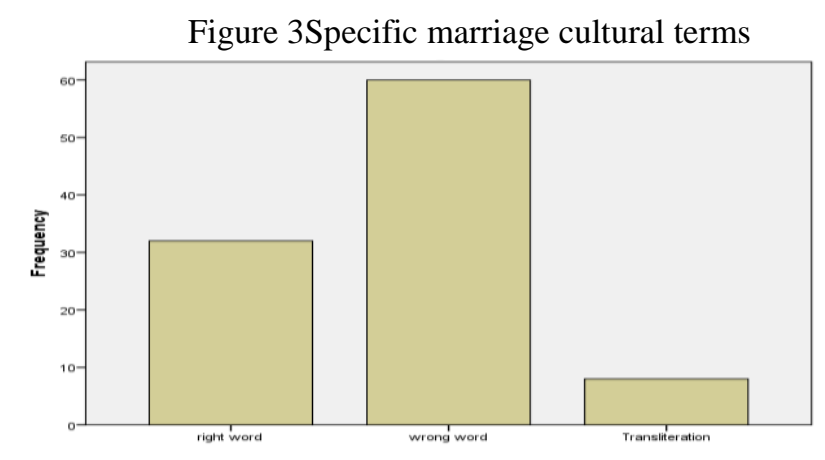




\section{Findings of the Interviews}

The first lecturer assumed that, the prime difficulty in translatingspecific cultural concepts is because of its conventional meaning which should be remembered during translation. Meanwhile, the second interviewee mentioned that specific cultural concepts are simply challenging to understand or to render because they are specific to a given culture in terms of their semantic denotation,linguistic structure and, more importantly, their socio-cognitive relevance. In addition, the third lecturer affirmed that the major obstacle in translating specific cultural concepts is that most of the learners do not have an adequate explanation to cultural concepts; making it challenging to identify, understand and translatein the second language. The fourth lecturer mentioned that the students' incapability to comprehend the context of the cultural concepts is one of the chief difficulties.

\section{Discussion of interview responses}

Findings related to problems faced byundergraduate students in translating specific cultural concepts from the Arabic language into the English language depict thatnearly all of the students find it hard to get the correspondence of the specific cultural concepts that were used in this test, a fact that is agreeing with findings reported by Bahameed, 2008. This finding also corresponds with Aldahesh (2008) research findings that emphasizes the inability to get the sameness is one of the most serious difficulties in translation.

The outcomes additionally showed that selecting and determining the suitable translation process was an additional difficulty the students faced. Several students either used literal translation or glossing method without providing any note or information to the target language reader. The findings also showed that the students were extremely affected by their culture, and this is realized in their translation. Cultural dissimilarities arean important factor in making the translation task hard for translators in general and students in particular. This outcome agreed with Badavi (2008)who affirmed that guessing strategies and literal translation remained common among English as a foreign language to Saudi prospective teachers.

Furthermore, the outcomes showed that the reasons behind these difficulties were the absence of cultural consciousness among the participants. This finding agreed withOlk (2003) who mentioned that students with insufficient knowledge about the English culture not being able to provideproper translation.

Finally, the results show that a huge gap between Arabic language and English language cultures is one of the causes for the students' inadequate translation. This settles well with Nida (1945) who claims that "no translation that attempts to bridge a wide cultural gap can hope to eliminate all traces of the foreign setting".

\section{Conclusion}

The data collected throughthe two instruments, the test and interview showed that undergraduate students from Al Imam AlMahdi University in Sudan faced several problems in translating specific cultural concepts from Arabic language into the English language such as disability to get a suitable correspondence and incapacity to apply the appropriate methods in translating. Literal translation and cultural effect resulted in the inadequate representation from students in the test. In the interview sessions, the lecturers explained the ideas behind these obstacles. Through the results given, it was obvious that unfamiliarity with the two cultures, inappropriate translation methods and approaches, were the main causes for the weak translation.

All respondents in the interviews admitted that familiarizing students with their target culture is a must. This can be achieved by providing additional programs that focuses on more training in translating specificculturalconcepts. Thisprogram will give the trainee more opportunitiesto deal with the challenge of specific culturalconcepts. Nevertheless, the outcomes of this paper cannot be generalised beyond the chosen respondents.

\section{References}

[1] ABBADI, R. 2008. An empirical study of problems faced by English-Arabic translation professionals: a corpus based analysis| Macquarie University ResearchOnline.

[2] AL-MASRI, H. 2009. Translation and Cultural Equivalence: A Study of Translation Losses in Arabic Literary Texts. Journal of Language \& Translation, 10, 7-44.

[3] AZIZ, Y. Y. \& LATAIWISH, M. S. 2000. Principles of translation, Department of English, University of Garyounis.

[4] BADAVI, M. 2008. Investigating EFL Prospective Teacher's Ability to Translate Culture-Bound Expressions. Online Submission.

[5] BAHAMEED, A. 2008. Hindrances in Arabic-English Intercultural Translation. Translation Journal, 12, 3.

[6] BEKKAI, M. 2010. The Influence of Culture on Arabic/English/Arabic Translation of Idioms and Proverbs.

[7] DEEB, Z. A. 2005. A taxonomy of translation problems in translating from English to Arabic. PhD, Newcstle University.

[8] DWEIK, B. S. \& SHAKRA, M. M. A. 2011. Problems in Translating Collocations in Religious Texts from Arabic into English. The Linguistics Journal, 5, 5-41.

[9] GHUSSAIN, A. \& AL LATIF, R. A. 2003. Durham E-Theses.

[10] MAASOUM, S. M. H. \& DAVTALAB, H. 2011. An Analysis of Culture-specific Items in the Persian Translation of "Dubliners" Based on Newmark's Model. Theory and Practice in Language Studies, 1, 1767-1779.

[11] NIDA, E. A. 1945. Linguistics and ethnology in translation problems. In Word, 1, 194-208.

[12] OLK, H. 2003. Cultural knowledge in translation. ELT journal, 57, 167-174. 
[13] PALUSZKIEWICZ-MISIACZEK, M. Strategies and Methods in Dealing with Culture Specific Expressions on the Basis of PolishEnglish Translations of Certain Administrative and Institutional Terms. Proceedings from the Eighth Conference of English, American and Canadian Studies:(linguistics, methodology and translation), 2005. Masaryk University, 243.

[14] SALEH, K. A. H., EL-ISA, S., SAMEER, E., AN, O. \& HIRZALLAH, R. 2011. Translating Restaurants' Menus From English Into Arabic: Problems And Strategies.

[15] SHAMMAS, N. A. 2010. Problems Encountered by MA Translation Students at Arab

[16] Universities. The Second Jordan International Conference on Translation. Petra

[17] University: Amman, Jordan.

[18] SHOBAKY, B. A. N. S. I. H. 2008. Translation of Cairene Colloquial Arabic

[19] In Selected Novels by Naguib Mahfouz:

[20] Semantico-Communicative Approach. Master of Arts, Zagazig University.

[21] SHUNNAQ, A. 1993. Lexical Incongruence in Arabic-English Translation Due to Emotiveness in Arabic. Turjman, 2, 37-63.

[22] WU, J. 2008. The Analysis of Cultural Gaps in Translation and Solutions. English Language Teaching, 1, P123.

[23] ZUGHOUL, M. R. \& ABDUL-FATTAH, H. 2003. Translational collocational strategies of Arab learners of English: A study in lexical semantics. Babel, 49, 59-81. 